\title{
Instrumented spherical micro-indentation of plasma-sprayed coatings
}

\author{
J. Alcalá ${ }^{a, *}$, F. Gaudette ${ }^{a}$, S. Suresh ${ }^{a}$, S. Sampath ${ }^{b}$ \\ ${ }^{a}$ Department of Materials Science and Engineering, Massachusetts Institute of Technology, Cambridge, MA 02139, USA \\ ${ }^{\mathrm{b}}$ Center for Thermal Spray Research, Department of Materials Science and Engineering, State University of New York, Stony Brook, \\ NY 11794-2275, USA
}

Received 31 October 2000; received in revised form 27 February 2001

\begin{abstract}
The mechanical response of plasma-sprayed coatings is studied by recourse to instrumented spherical micro-indentation. It is shown that the elastic moduli of the coatings can be determined in a more reliable and reproducible manner with instrumented spherical indentation than prior (Knoop) indentation methods, while at the same time minimizing damage to the coating during indentation. The results show that the values of the elastic moduli, $E$, of air plasma-sprayed (APS) materials are much lower than those of vacuum plasma-sprayed (VPS) materials. The VPS deposits are more homogeneous at a microstructural level as splat formation, microcracking and the development of oxide scales are suppressed. Such homogenization increases the value of $E$ to the point where it becomes similar to that of fully dense materials. Larger amounts of inelastic flow occur in APS deposits as compared with VPS deposits. This flow is associated with fracture and sliding of splats. (C) 2001 Elsevier Science B.V. All rights reserved.
\end{abstract}

Keywords: Coatings; Plasma-sprayed coatings; Micro-indentation

\section{Introduction}

Plasma-sprayed coatings are widely used in structural components for the purpose of providing environmental stability, wear and thermal protection [1-4]. The plasma-spray process is carried out by feeding powders into a plasma torch where the material is melted and propelled as molten particles towards the substrate. A coating builds-up as the substrate is exposed to the flux of molten material for a period of time. Plasma-sprayed coatings consist of disc-shaped microstructural units (also referred to as 'splats') which acquire such geometry as a result of the impingement of the molten material onto the substrate $[2,5]$.

Enhancements in processing techniques have emerged in order to improve the mechanical response and life of

\footnotetext{
* Corresponding author. Present address: Department of Materials Science and Metallurgical Engineering, Universitat Politècnica de Catalunya, E.T.S. Ingenieros Industriales. UPC, Avda. Diagonal 647, Barcelona 08028, Spain. Tel.: + 34-93-4016287; fax: + 34-934016706.

E-mail address: alcala@cmem.upc.es (J. Alcalá).
}

plasma-sprayed coatings. An important advance has been the development of a system where the deposition is conducted inside a low pressure inert-gas filled chamber. The materials processed using this system are referred to as low-pressure plasma-sprayed or vacuum plasma-sprayed (VPS) deposits [5]. The improvements resulting from this technique over conventional air plasma-spray are that (i) oxidation of the deposited particles is suppressed, and (ii) VPS coatings are maintained at a higher temperature during processing due to the larger length of the plasma torch and the reduced heat transfer in the low pressure environment. The latter promotes high-temperature interaction between splats resulting in more uniform coatings.

Knowledge of the mechanical performance of plasma-sprayed coatings is of critical importance. As a result, the assessment of the relationship between their mechanical properties and processing variables is essential. This may require the removal of the deposit from the substrate in such a way that the integrity of the coating is preserved. This procedure is then followed by uniaxial mechanical testing of the remaining coatings. 
Alternatively, indentation tests can be regarded as a basic tool for the mechanical characterization and quality control of plasma-sprayed materials.

Conventional indentation tests provide a measure of hardness; however, such an evaluation does not give a true insight into the basic aspects of the mechanical response because hardness is a combination of elastic and plastic properties. In addition to hardness evaluations, more advanced micro- and macro-indentation experiments have been used to assess the mechanical response of plasma-sprayed coatings [6,7]. The main drawback of these experiments is that, in the case of sharp indentation, Young's modulus $(E)$ is evaluated on unloading using optical measurements of the elastic recovery at the corners of the imprint [6]. Since these measurements are conducted upon the inducement of a large amount of material damage on loading, the computed value of $E$ may not be accurate in ceramic coatings, which exhibit pronounced microcracking. On the other hand, spherical indentation experiments can be performed without inducing such damage. Thus, accurate estimation of $E$ even for materials which are prone to microcracking can be obtained. The inelastic response of the deposits measured by spherical macroindentation is, however, influenced by the substrate because the contact area is large as compared with the thickness of the coatings [7]. This makes it difficult to differentiate between the actual inelastic response of the plasma-sprayed material and the inelastic response of the coating-substrate composite.

Instrumented spherical micro-indentation can potentially offer a useful tool for evaluating the properties of plasma-sprayed coatings, which overcomes the foregoing problems. The indenter size and the indentation load can be chosen such that the stress field of indentation is confined entirely within the coating; the effects of the substrate on indentation response are thereby eliminated. In addition, the indentation contact area can be induced, in most cases, to encompass a number of grains in the coating in order to sample the average properties over several microstructural units. Furthermore, the lack of a stress singularity and the low loads employed for spherical micro-indentation preclude the inducement of significant damage during indentation of porous plasma-spray coatings, facilitating the measurement of their Young's moduli. Since the spherical micro-indentation is thus likely to lead to an extended elastic deformation in the early stages of loading [8], any elastic residual stresses which exist in the coating from rapid cooling and thermal expansion mismatch are not expected to have any effect on the indentation behavior [9].

The objectives set for this work were.

- To study the mechanical response of plasma-sprayed materials by recourse to instrumented spherical micro-indentation. This technique allows the measure- ment of continuous load $(P)$ versus depth of penetration $(h)$ curves within the elastic regime which enables an accurate evaluation of Young's modulus, $E$ [8]. Due to the relatively small length scales involved in micro-indentation tests, $P-h$ curves also provide an assessment of the capacity of the coating to accumulate inelastic deformation, which is free of any influence from the substrate.

- To establish the differences between the mechanical response of air plasma-sprayed (APS) and VPS materials using instrumented micro-indentation. The use of this indentation technique is expected to provide an accurate and cost-effective evaluation of the elasto-plastic response of plasma-sprayed deposits.

- To study relevant micro-deformation mechanisms in plasma-sprayed deposits in an attempt to establish a link between microstructural factors, which are controlled by the manufacturing process, and the mechanical response of the coatings.

\section{Materials}

$\mathrm{NiAl}$ intermetallic, $\mathrm{Ni}-\mathrm{Cr}-\mathrm{Al}-\mathrm{Y}$ and $\mathrm{Al}_{2} \mathrm{O}_{3}$ powders were plasma-sprayed onto 1020 steel substrates both in an air and in a low-pressure inert gas environment. The substrates were mounted on a cylindrically shaped rotating carousel placed in front of the plasma torch. Longitudinal motion of the torch relative to the axis of the carousel provided uniform thickness deposits. A commercial Sulzer Metco PT F4 system was used for deposition. Plasma-spraying was conducted in a single step, that is, without interruptions of the spray sequence to prevent overheating of the substrate [7]. The substrates reached steady-state temperatures of $\sim 100$ and $\sim 900^{\circ} \mathrm{C}$ in air and vacuum plasma-spray conditions, respectively. Gun amperage and gun voltage were set to $600-650 \mathrm{~A}$ and $\sim 67 \mathrm{~V}$, respectively. Spray distance was $\sim 250 \mathrm{~mm}$. The size of the plasmasprayed powders ranged between 7 and $38 \mu \mathrm{m}$. Additional experiments were also carried out in fully dense $\mathrm{NiAl}$ intermetallic and $\mathrm{Al}_{2} \mathrm{O}_{3}$ (AD 999, Coors Ceramics, Golden, $\mathrm{CO}$ ) for comparison with plasma-sprayed materials.

The following describes the microstructure of the coatings at the cross-section of the specimens (i.e. normal to the plasma-spray direction). Dark streaks appear between splats in $\mathrm{NiAl}$ and $\mathrm{Ni}-\mathrm{Cr}-\mathrm{Al}-\mathrm{Y}$ deposits when processed in an air environment (Fig. 1). Some of the streaks were actually inter-lamellar voids (i.e. pores which separate neighboring splats) as evidenced by resolving topographical features on the crack faces. X-ray energy dispersive spectra (EDS) consistently showed that large $\mathrm{Al}$ and $\mathrm{O}$ peaks are present in all of the streaks, suggesting $\mathrm{Al}_{2} \mathrm{O}_{3}$ scale formation. Un- 
cracked $\mathrm{Al}_{2} \mathrm{O}_{3}$ scales were detected by $\mathrm{SEM}$ as streaks with a lighter appearance. Although some porosity was readily detected in VPS $\mathrm{NiAl}$ and VPS $\mathrm{Ni}-\mathrm{Cr}-\mathrm{Al}-\mathrm{Y}$ deposits, $\mathrm{Al}_{2} \mathrm{O}_{3}$ formation and microcracking were fully suppressed, resulting in more uniform coatings which do not contain dark streaks (Fig. 2). Equiaxial grains of $\sim 5 \mu \mathrm{m}$ were found in the case of VPS $\mathrm{Ni}-\mathrm{Cr}-\mathrm{Al}-\mathrm{Y}$, where the lamellar microstructure vanished completely.

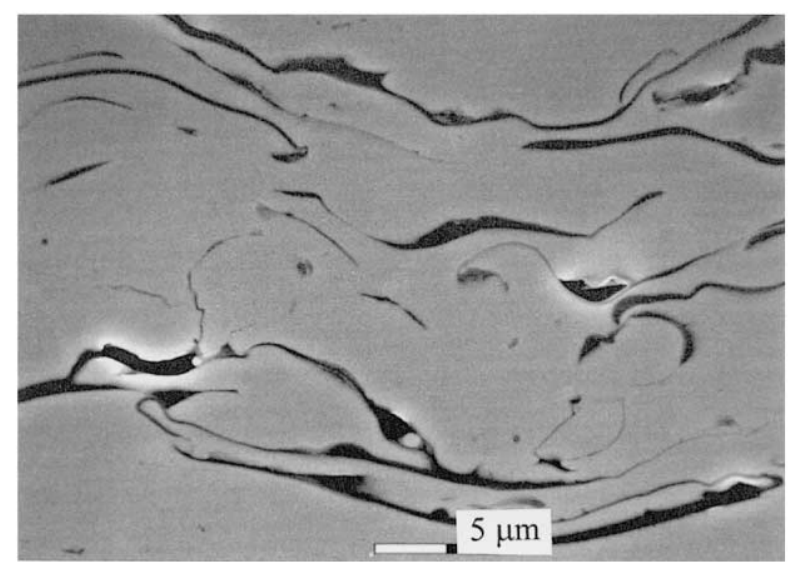

(a)

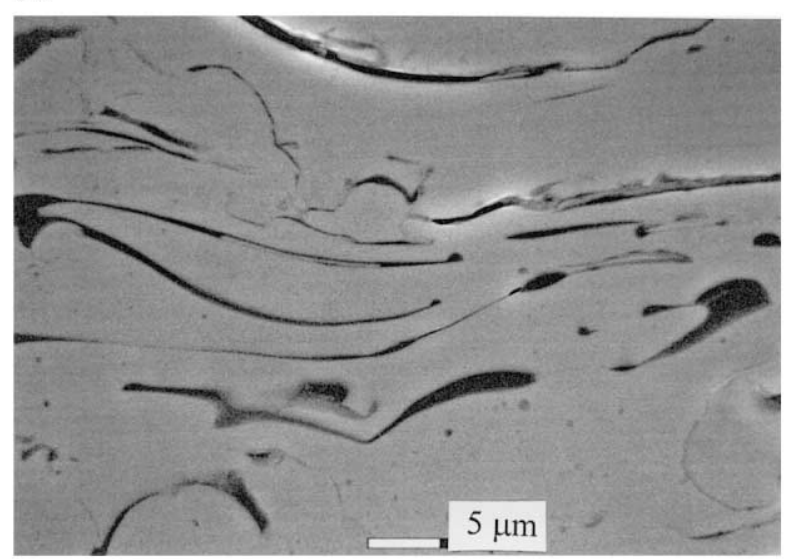

(b)

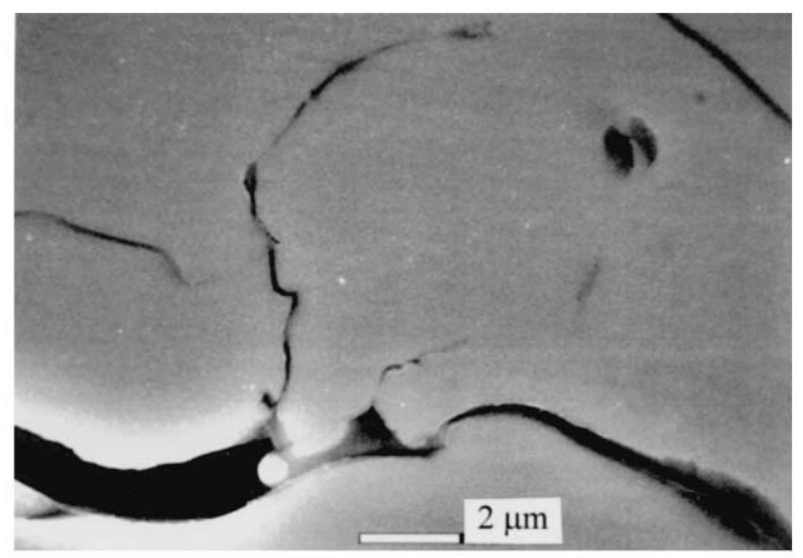

(c)

Fig. 1. Microstructural aspects of the cross-section of the deposits. (a) $\mathrm{NiAl}$, (b) $\mathrm{Ni}-\mathrm{Cr}-\mathrm{Al}-\mathrm{Y}$, (c) appearance of the microstructure of NiAl at high magnification.

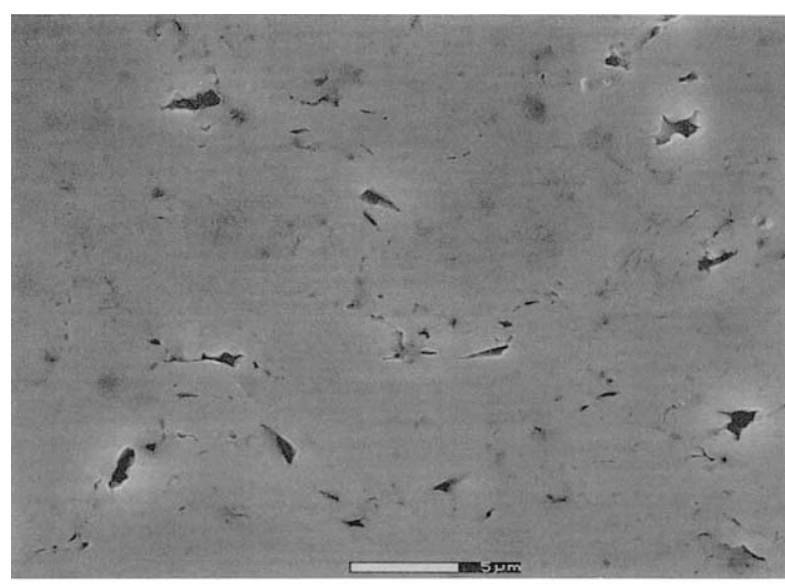

(a)

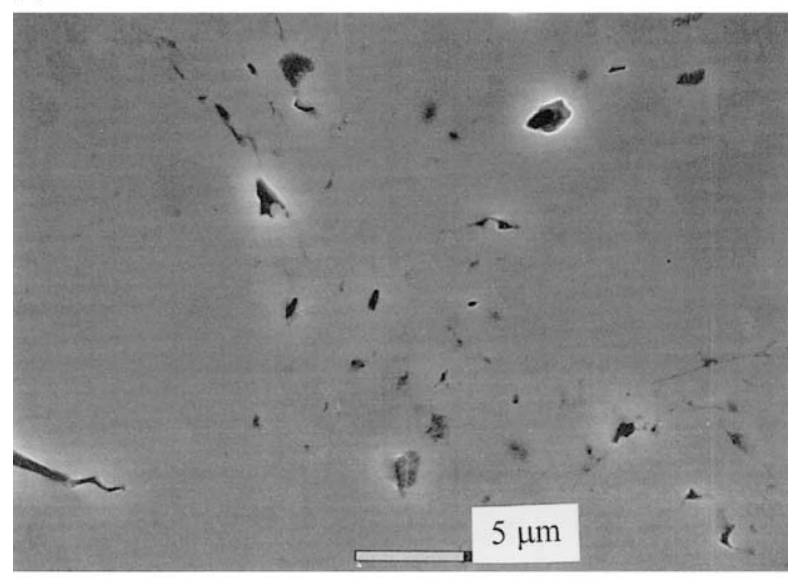

(b)

Fig. 2. Microstructure at the cross-section of VPS deposits. (a) NiAl, (b) $\mathrm{Ni}-\mathrm{Cr}-\mathrm{Al}-\mathrm{Y}$.

The microstructural differences between APS and VPS deposits are due to the higher processing temperatures reached during vacuum plasma-spraying which improves inter-splat cohesion, and to the reduced amount of oxygen in the environment which prevents oxidation of the boundaries between splats [5]. The microstructural features of VPS $\mathrm{Al}_{2} \mathrm{O}_{3}$ are similar to those of APS $\mathrm{Al}_{2} \mathrm{O}_{3}$, see Fig. 3. Splat formation occurred in both types of $\mathrm{Al}_{2} \mathrm{O}_{3}$ coatings with inter- and intra-lamellar microcracks evident by SEM as shown in Fig. 3c. The splats in VPS and APS alumina were $\sim 5-20 \mu \mathrm{m}$ in length and $\sim 3 \mu \mathrm{m}$ in width.

\section{Indentation experiments}

Instrumented indentation experiments were conducted using the fixture described in $[8,10]$. This arrangement allows $P-h$ curves to be measured in situ with load and depth resolutions of $0.01 \mathrm{~N}$ and $0.01 \mu \mathrm{m}$, respectively. The fixture was fitted into a screw-driven testing machine, and indentation experiments were car- 
ried out under displacement control. A WC-10 wt.\% Co spherical indenter with $E=475 \mathrm{GPa}$, Poisson's ratio, $v=0.22$ and diameter, $D=1.59 \mathrm{~mm}$ was used in the experiments [8]. The sphere was in contact with the specimen and the back surface of the indenter which is also made of WC-10 wt.\% Co (Fig. 4). The indented surfaces of the coatings were polished to a mirror finish using diamond paste. Polishing was performed with low applied pressure and by gradually decreasing the size of the diamond paste from 30 to $1 \mu \mathrm{m}$.

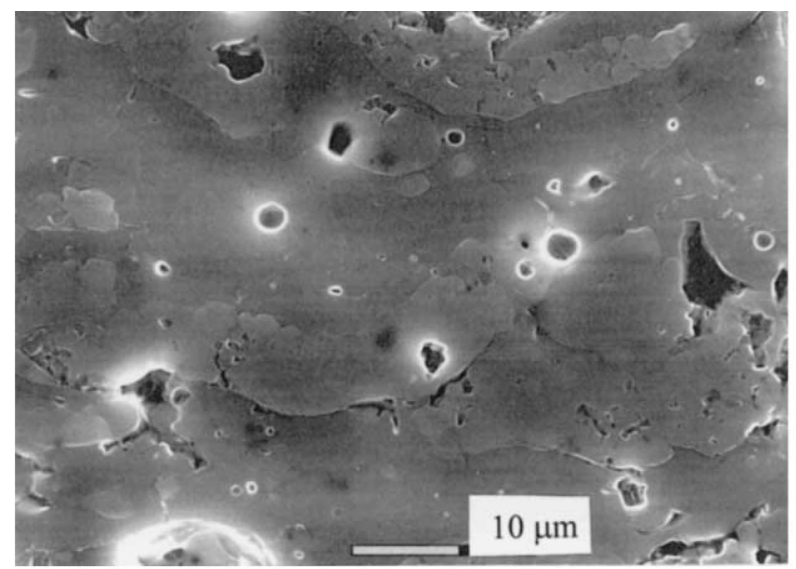

(a)

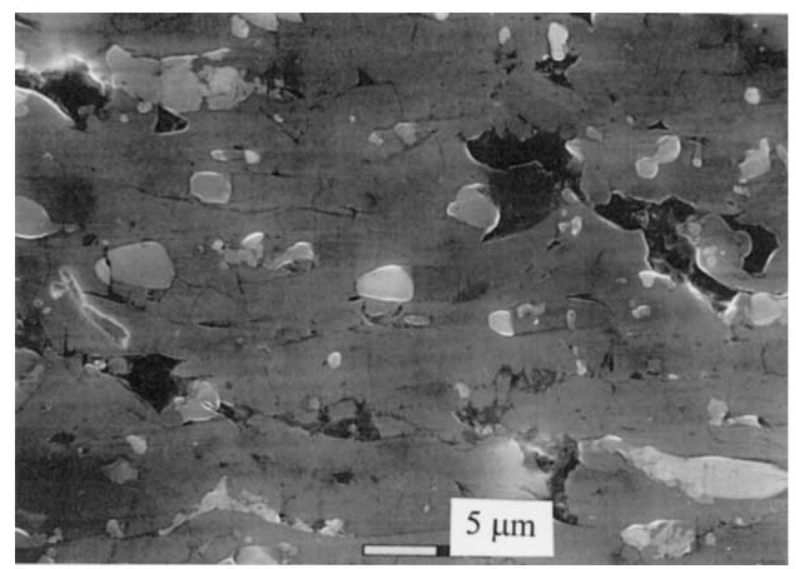

(b)

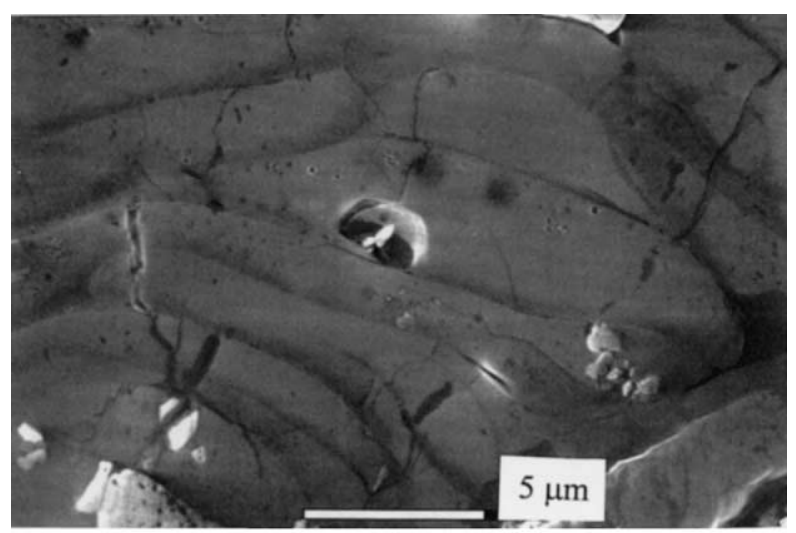

(c)

Fig. 3. $\mathrm{Al}_{2} \mathrm{O}_{3}$ deposits processed under (a) air plasma-spray, (b) vacuum plasma-spray, (c) detail of the splat morphology.

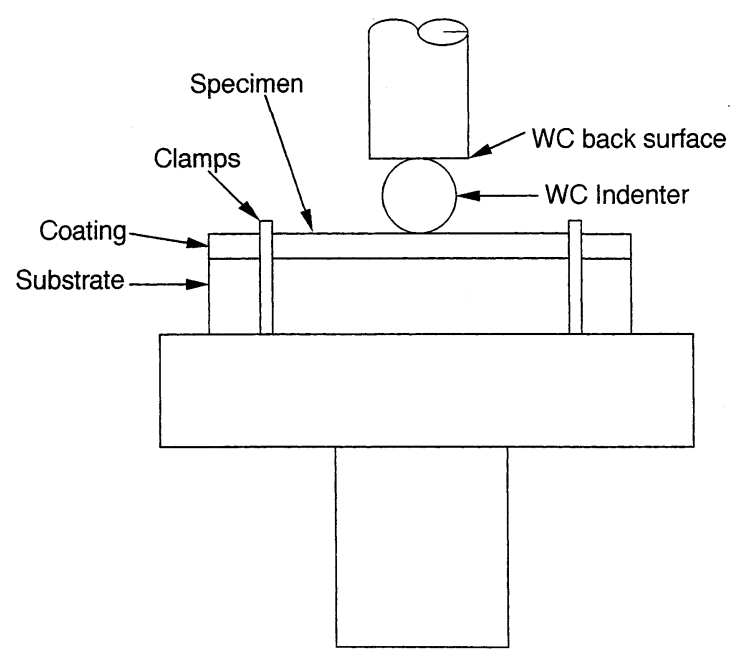

Fig. 4. Schematic of the indentation fixture.

An important aspect of spherical micro-indentation is that the contact response is elastic at the commencement of loading. Hence, Young's modulus $(E)$ can be found from the solution derived by Hertz for the elastic contact of spherical bodies [8]. Hertz's solution for a flat surface (with an infinite radius of curvature) in contact with a spherical indenter, is given by

$$
P=C h^{3 / 2}, \quad C=\frac{2 \sqrt{2}}{3} E^{*} D^{1 / 2}
$$

where $E^{*}$ is the composite Young's modulus of the specimen-indenter system defined as

$E^{*}=\left(\frac{1-v_{1}^{2}}{E_{1}}+\frac{1-v_{2}^{2}}{E_{2}}\right)^{-1}$

where $E$ and $v$ are the Young's moduli and Poisson's ratios of the bodies in contact, and subscripts 1 and 2 refer to the sphere and the flat surface, respectively.

As noted above, in the present experiments contact occurred between the back surface and the sphere, and between the specimen and sphere, Fig. 4. Thus, the above equations need to be corrected for such 'double contact' conditions. Under these conditions, the total (measured) displacement is computed by adding the depth of penetration of the indenter into the back surface to that of the indenter into the specimen, where each of these contacts is modeled using Eqs. (1) and (2). Then, the measured depth of penetration is given by [8]

$h=\left(\frac{P}{C_{1}}\right)^{2 / 3}+\left(\frac{P}{C_{2}}\right)^{2 / 3}$

where $C_{1}$ and $C_{2}$ represent the contact compliance between the back surface and the indenter, and between the indenter and the specimen, respectively. Rearranging Eq. (3), the $P-h$ relation becomes

$P=C_{2}\left\{\left(\frac{C_{2}}{C_{1}}\right)^{2 / 3}+1\right\}^{-3 / 2} h^{3 / 2}$. 
Eq. (4) shows that the contact response can be modeled by the generic expression $P=C h^{1.5}$, where $C$ is the total contact compliance. Thus, the evolution of $C$ with the applied load, $P$, can be calculated by numerical integration of the $P-h$ data so that

$C=\frac{2.5}{h_{\mathrm{f}}^{2.5}} \int_{h_{\mathrm{o}}=0}^{h_{\mathrm{f}}} P \mathrm{~d} h$,
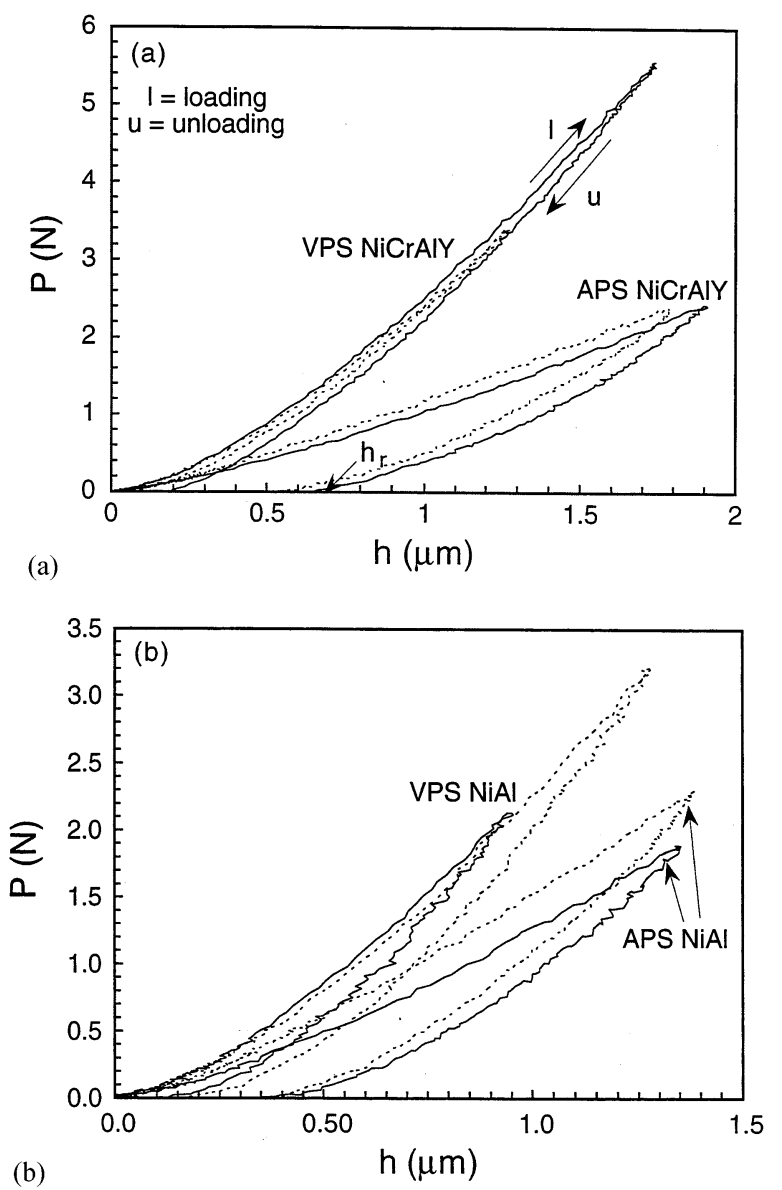

(b)

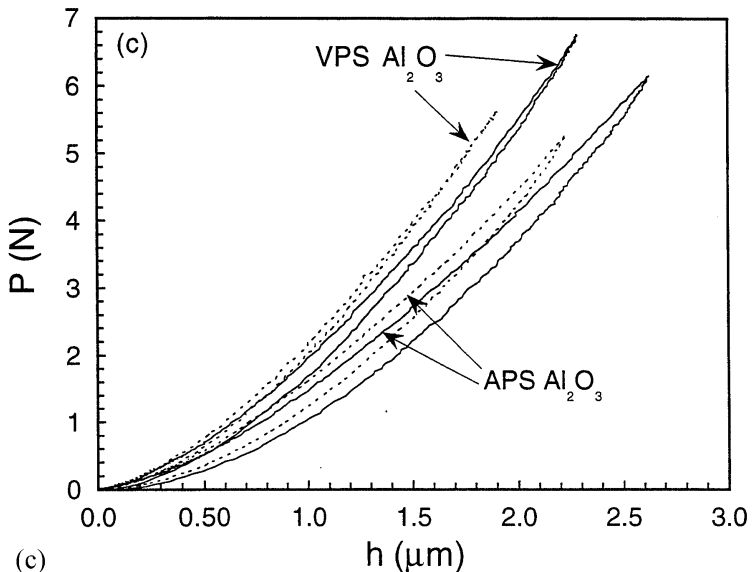

(c)

$$
\mathrm{h}(\mu \mathrm{m})
$$

Fig. 5. $\mathrm{P}-h$ curves of VPS and APS coatings. (a) $\mathrm{Ni}-\mathrm{Cr}-\mathrm{Al}-\mathrm{Y}$, (b) $\mathrm{NiAl}$, and (c) $\mathrm{Al}_{2} \mathrm{O}_{3}$. Two different experiments are presented for each material using dashed and continuous lines which approximately represent the extend of experimental scatter. where $h_{\mathrm{o}}$ is the position of the indenter tip at the commencement of contact, which is set to zero, and $h_{\mathrm{f}}$ is the value of the measured depth of penetration at which $C$ is computed. This provides the constant value of $C$ best fitting the experimental $P-h$ measurements from which the Young's modulus of the specimen can be calculated [8]. A gradual decrease in the value of $C$ as the applied load increases is indicative of the development of inelastic deformation in the material (see Section 4.1). In the calculation of Young's modulus, the value of $C_{1}$ has to be computed from Eqs. (1) and (2) using the values of $E$ and $v$ of the spherical indenter and the back surface. In the present case, both the sphere and the flat surface are of WC-10 wt.\% Co which yields $C_{1}=9.3 \mathrm{~N} \mathrm{\mu m}^{-1.5}$. Hence, as the value of $C$ is computed from Eq. (5) using the experimentally measured $P-h$ curve, $C_{2}$ can be calculated from Eq. (4). Finally, the value of $E^{*}$ for the composite specimen-indenter is obtained by substituting $C_{2}$ into Eq. (1). The computed value of $E^{*}$ is substituted into Eq. (2) to find the value of $E_{2} / 1-v_{2}^{2}$, where in the present case $E_{1}=$ $475 \mathrm{GPa}$ and $v_{1}=0.22$ for the $10 \mathrm{wt} . \% \mathrm{Co}-\mathrm{WC}$ indenter. It is noted that in order to estimate $E_{2}$ for the materials under study, a value of $v_{2}=0.3$ was assumed in all cases. The influence of this assumption on the final outcome is small as changes of $30 \%$ in $v$ only affect the computed values of $E$ by $\sim 5 \%$.

\section{Results and discussion}

\subsection{Elastic moduli of coatings}

Fig. 5 shows the $P-h$ curves for the plasma-sprayed materials under study, and Fig. 6 presents their $C-P$ curves calculated from Eq. (5) ${ }^{1}$. The residual depth of penetration, $h_{\mathrm{r}}$, evident in the $P-h$ loops on complete unloading is an indication of the capacity of the materials to accumulate inelastic deformation at a given peak load, Fig. 5a. In Fig. 6a and b, the occurrence of inelastic flow is associated with the gradual decrease in $C$ with an increase in $P$. It is stressed that the value of $C$ should be constant for elastic deformation, as it measures the contact compliance which depends only on the elastic constants of the materials (see Eqs. (1) and (2)). Therefore, a decrease in $C$ during loading is related to a decrease in the stiffness of the specimen due to inelastic deformation.

In view of the foregoing discussion, the decrease in $C$ with increase in $P$ shown in Fig. 6 for some APS

\footnotetext{
${ }^{1}$ The $C-P$ curves are presented here after the initial pre-Hertzian regime (i.e. for $P$ larger than $\sim 0.5 \mathrm{~N}$ ) where fluctuations in the value of $C$ occur due to (i) experimental scatter in the data used to compute $C$, and (ii) deviations from the perfectly spherical indenter geometry [8].
} 

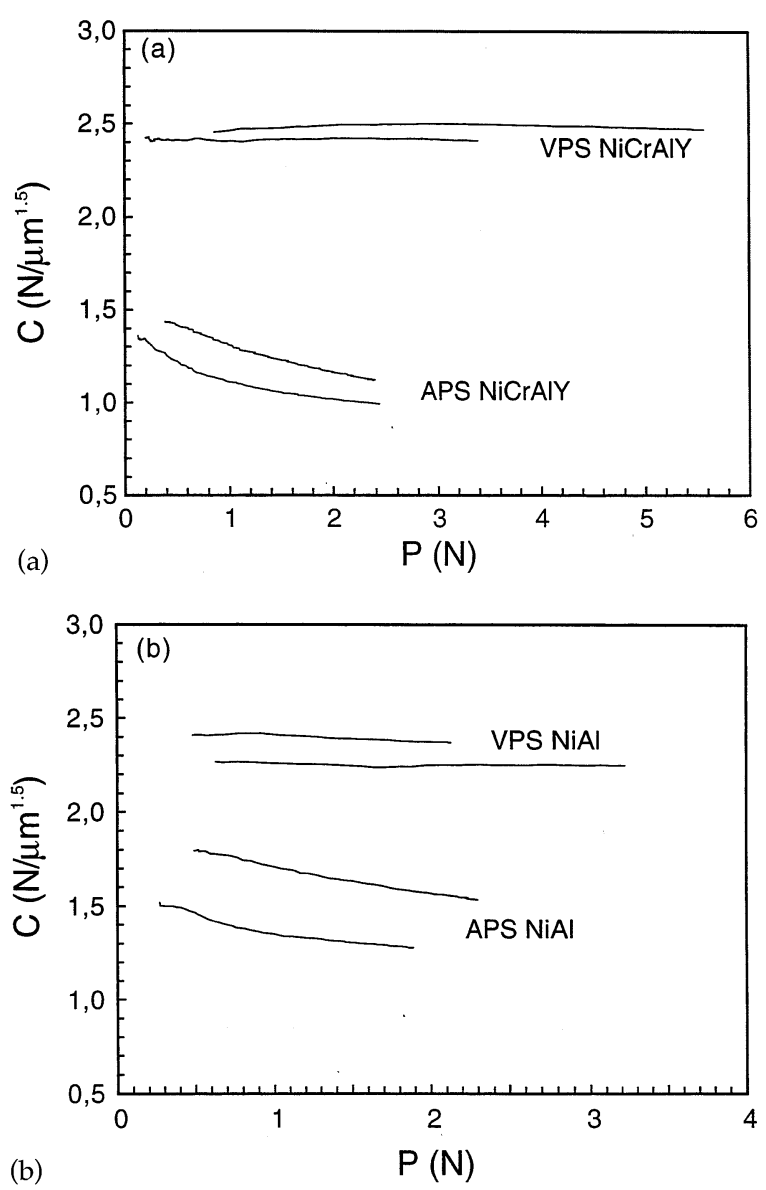

(b)

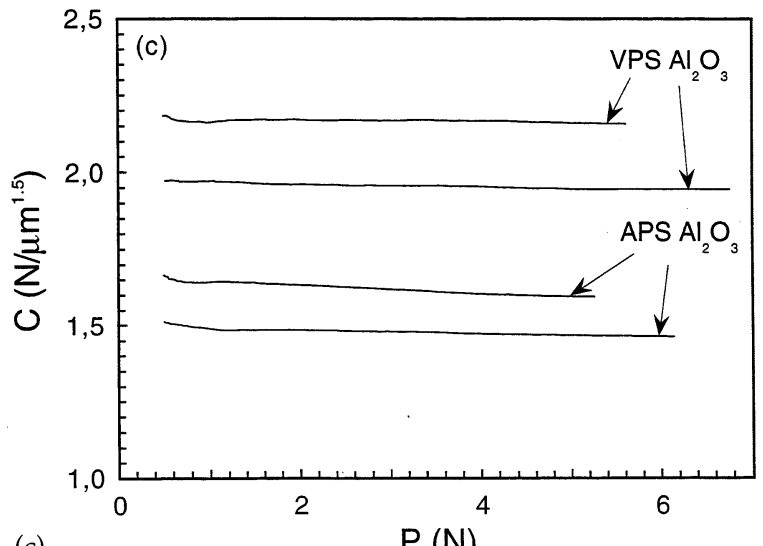

(c)

Fig. 6. $C-P$ curves for the experiments showed in Fig. 5. (a) $\mathrm{Ni}-\mathrm{Cr}-\mathrm{Al}-\mathrm{Y}$, (b) $\mathrm{NiAl}$, and (c) $\mathrm{Al}_{2} \mathrm{O}_{3}$.

coatings indicates that these materials are capable of undergoing larger amounts of inelastic deformation than VPS materials of identical composition. In terms of their decreasing capacity to accumulate inelastic deformation, the APS materials can be ranked as $\mathrm{Ni}-$ $\mathrm{Cr}-\mathrm{Al}-\mathrm{Y} \rightarrow \mathrm{NiAl} \rightarrow \mathrm{Al}_{2} \mathrm{O}_{3}$, where inelastic flow is easily promoted in APS $\mathrm{Ni}-\mathrm{Cr}-\mathrm{Al}-\mathrm{Y}$ and $\mathrm{NiAl}$ for which $C$ decreases gradually. These results show the strong tendency of plasma-sprayed coatings to undergo inelastic flow as compared with fully dense materials. In this regard, the plasticity induced in APS materials is of the same magnitude as that in the low carbon steel used in our prior work [8] (see Section 4.4 for the micromechanisms which account for such inelastic responses). It is noted that the inelastic response induced by spherical indentation through its strong hydrostatic stress field does not imply that the coatings would also have a high fracture energy.

Table 1 contains the values of $E$ for the materials under study as calculated using the procedure described in Section 3, where the $C-P$ curves for APS NiAl and APS $\mathrm{Ni}-\mathrm{Cr}-\mathrm{Al}-\mathrm{Y}$ shown in Fig. 6 are linearly extrapolated to zero load to find the elastic contact compliance. The scatter range shown in Table 1 for $E$ in each case is derived from at least seven indentation tests. From these results it is evident that VPS materials have larger values of $E$ than those for APS deposits. The ratio, $\eta$, of the elastic modulus of the plasma-sprayed deposit to that of the fully dense material is considered a measure of the influence processing has on the elastic properties of plasma-sprayed materials. This ratio has a maximum for VPS materials, being $\sim 1$ in the case of VPS $\mathrm{Ni}-\mathrm{Cr}-\mathrm{Al}-\mathrm{Y}$ (where it is considered that the value of $E$ for fully dense $\mathrm{Ni}-\mathrm{Cr}-\mathrm{Al}-\mathrm{Y}$ is similar to that of $\mathrm{Ni}-\mathrm{Cr}$ alloys; i.e. $E \sim 200 \mathrm{GPa})$. As $E$ is measured under elastic contact conditions, values of $\eta$ lower than 1 can only be associated with the influence that porosity and microcracking of the fresh material have on the elastic contact compliance.

The larger $\eta$ for VPS deposits, as compared with APS deposits of similar composition, is consistent with the decrease in porosity, inter-lamellar cracking and removal of oxide layers which occur under vacuum plasma-spray conditions. Such an improvement in microstructural homogenization is particularly noticeable in the case of VPS $\mathrm{Ni}-\mathrm{Cr}-\mathrm{Al}-\mathrm{Y}$, where the lamellar structure vanished completely, giving rise to equiaxial grain formation. This degree of homogenization was

Table 1

Spherical indentation results

\begin{tabular}{lcc}
\hline & $E_{\mathrm{s}}(\mathrm{GPa})^{\mathrm{a}}$ & $\eta^{\mathrm{b}}$ \\
\hline $\mathrm{NiCrAlY}$ (VPS) & $195 \pm 9$ & $0.98 \pm 0.05^{\mathrm{c}}$ \\
$\mathrm{NiCrAlY}$ (APS) & $80 \pm 12$ & $0.40 \pm 0.06$ \\
$\mathrm{NiAl}$ (fully dense) & $232 \pm 9$ & 1.00 \\
$\mathrm{NiAl}$ (VPS) & $110 \pm 18$ & $0.48 \pm 0.07$ \\
$\mathrm{NiAl}$ (APS) & $91 \pm 9$ & $0.39 \pm 0.04$ \\
$\mathrm{Al}_{2} \mathrm{O}_{3}$ (fully dense) & $395 \pm 20$ & 1.00 \\
$\mathrm{Al}_{2} \mathrm{O}_{3}$ (VPS) & $146 \pm 34$ & $0.37 \pm 0.09$ \\
$\mathrm{Al}_{2} \mathrm{O}_{3}$ (APS) & $86 \pm 15$ & $0.22 \pm 0.04$ \\
\hline
\end{tabular}

\footnotetext{
a Young's modulus from spherical indentation.

${ }^{\mathrm{b}} \eta=E_{\text {plasma-sprayed }} / E_{\text {fully dense }}$ (see text for details).

${ }^{\mathrm{c}} E_{\text {dense nickel }}=200 \mathrm{GPa}$.
} 
Table 2

Knoop indentation results

\begin{tabular}{lccc}
\hline & $E(\mathrm{GPa})^{\mathrm{a}}$ & $H(\mathrm{Gpa})$ & $a / b^{\mathrm{b}}$ \\
\hline $\mathrm{NiCrAlY}$ (VPS) & $105 \pm 20$ & $4.9 \pm 0.3$ & 0.12 \\
$\mathrm{NiCrAlY}$ (APS) & $27 \pm 6$ & $2.1 \pm 0.2$ & 0.10 \\
$\mathrm{NiAl}$ (fully dense) & $68 \pm 20$ & $3.0 \pm 0.1$ & 0.12 \\
$\mathrm{NiAl}$ (VPS) & $102 \pm 30$ & $4.0 \pm 0.1$ & 0.12 \\
$\mathrm{NiAl}$ (APS) & $33 \pm 8$ & $1.9 \pm 0.2$ & 0.11 \\
$\mathrm{Al}_{2} \mathrm{O}_{3}$ (fully dense) & $310 \pm 100$ & $22.0 \pm 1.5$ & 0.11 \\
$\mathrm{Al}_{2} \mathrm{O}_{3}$ (VPS) & $294 \pm 80$ & $16.6 \pm 1.5$ & 0.11 \\
$\mathrm{Al}_{2} \mathrm{O}_{3}$ (APS) & $201 \pm 50$ & $10.6 \pm 1.0$ & 0.12 \\
\hline
\end{tabular}

a Young's modulus from Knoop indentation.
b Length of major diagonal/length of minor diagonal.

not achieved in $\mathrm{NiAl}$ and $\mathrm{Al}_{2} \mathrm{O}_{3}$ deposits; such a trend is in agreement with the lower diffusion rates in binary ordered intermetallics and ceramics as compared with the $\mathrm{Ni}-\mathrm{Cr}-\mathrm{Al}-\mathrm{Y}$ alloy. Hence, $\mathrm{NiAl}$ and $\mathrm{Al}_{2} \mathrm{O}_{3}$ would require much higher processing temperatures than $\mathrm{Ni}-$ $\mathrm{Cr}-\mathrm{Al}-\mathrm{Y}$ for similar levels of microstructural homogenization. Finally, a clear difference between the values of $E$ for APS and VPS $\mathrm{Al}_{2} \mathrm{O}_{3}$ is evident from Table 1 . In view of the microstructural similarities between these materials, see Section 2, it can only be speculated that such a difference in $E$ is due to improved bonding between the splats for VPS conditions which reduces the amount of inter- and intra-lamellar microcracks.

\subsection{Comparisons between instrumented micro-indentation and Knoop indentation}

It is important to compare the present evaluation of $E$ to that obtained by other indentation techniques. In the present technique, the material is elastic at the commencement of contact and $E$ is calculated based on elastic contact mechanics. This, however, is not the case with sharp indentation as permanent deformation occurs immediately upon the application of load. Previous evaluations of $E$ with a Knoop indenter involved optical measurement of the elastic recovery at the imprint [6,11]. Such measurements were used as input into equations where a generic elasto-plastic law was assumed a priori and calibrated experimentally. The weakness of such a method is that the assumed elastoplastic model may not be common to all materials. Also, since it is well-known that damage accumulation reduces the value of $E$ in ceramics, measurement of elastic recovery in sharp indents may not give an accurate representation of the response of the fresh (original) material, particularly when large amounts of microcracking are induced during indentation.

In order to determine how much the above considerations affect $E$ measurements from sharp indentation, complementary experiments were conducted with a Knoop indenter and the value of $E$ calculated from the elastic recovery of the imprint using $[6,11]$ $\frac{b^{\prime}}{a^{\prime}}=\frac{b}{a}-\frac{\alpha H}{E}$,

where $2 b^{\prime}$ is the length of the minor diagonal upon unloading; $2 a=2 a^{\prime}$ is the length of the major diagonal, which is assumed to remain constant on unloading; $2 b$ is the length of the minor diagonal under the applied peak load as calculated from the geometry of the Knoop diamond and the value of $2 a$; and $\alpha$ is a constant whose value is found to be 0.45 from experiments.

The results for $E$ computed from Eq. (6) are shown in Table 2, where a peak load of $10 \mathrm{~N}$ was used in the experiments for consistency with [6]. For most of the materials under study, the values of $E$ from sharp micro-indentation are lower than those obtained from instrumented spherical micro-indentation (it is emphasized that, as shown in [8], the latter technique gives $E$ values which are in agreement with those obtained from uniaxial tests). It is also noted that even by changing the value of $\alpha$, it was not possible to find uniform agreement between the actual values of $E$ measured by spherical micro-indentation and those computed from Eq. (6). Interference from the substrate in these measurements is minimized as the maximum depth of Knoop indentations was $\sim 10 \mu \mathrm{m}$, which is much smaller than the thickness of the coatings $(\sim 150 \mu \mathrm{m})$.

An important assumption of the present spherical micro-indentation methodology for measuring $E$ is that the contact response is not affected by the presence of residual stresses. This assumption is valid in the framework of linear elasticity where the principle of superposition implies that the stress fields induced by indentation can be calculated as if there were no initial residual stresses [9]. Therefore, the $P-h$ curves in the elastic regime are not affected by prior residual stresses. This consideration is important in the context of this work as it is well-known from X-ray and neutron diffraction as well as curvature measurements that large residual stresses (with magnitudes of several hundred $\mathrm{MPa}$ ) are induced in plasma-sprayed coatings during deposition [12,13]. Thus, it is desirable that the measured value of $E$ not be influenced by such stresses. Methods to extract the effects of residual stresses on plastic deformation during indentation are given in [9]

\subsection{Issues of size scales in instrumented spherical indentation}

Instrumented spherical micro-indentation results are intrinsically sensitive to microstructural size scales and it is, therefore, of interest to examine the key size scales of the process. For a given spherical indenter diameter, $D$, and depth of penetration, $h$, of the indenter into the coating, the indentation contact radius, $c$, is given by 
$c=\sqrt{\frac{h D}{2}}$

For the present case with $D=1.59 \mathrm{~mm}$ and $h \sim 1 \mu \mathrm{m}$ in the upper region of elastic indentation, it is seen that $c \sim 28 \mu \mathrm{m}$. Coatings with complex microstructures are

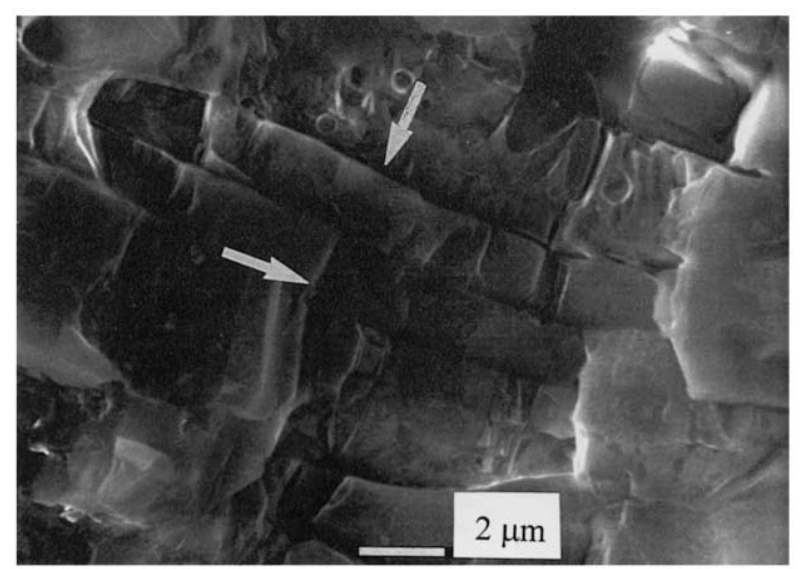

(a)

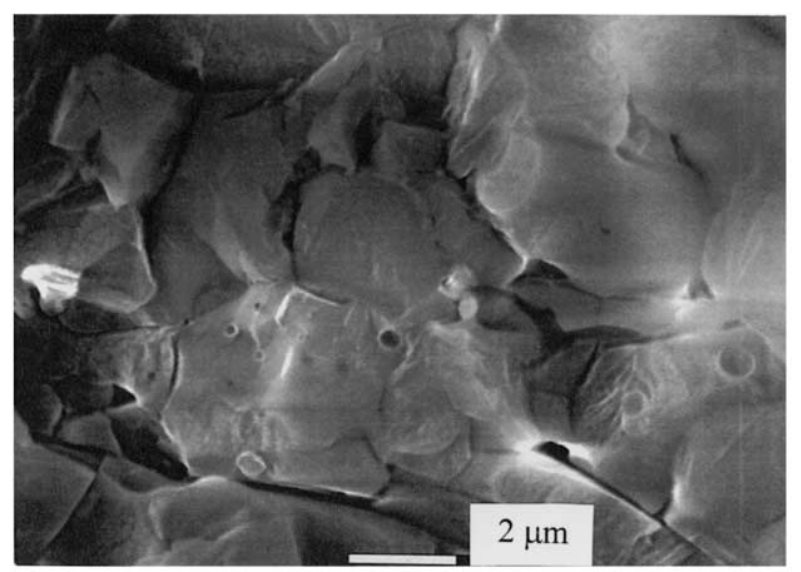

(b)

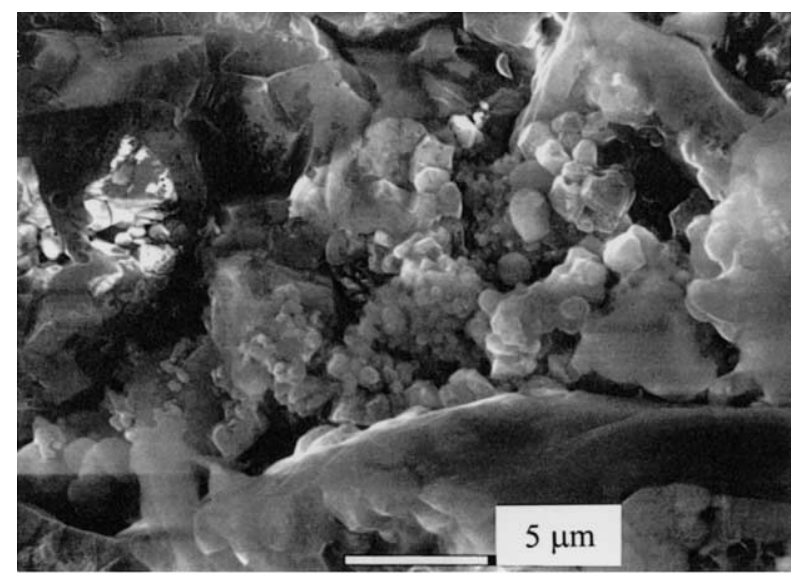

(c)

Fig. 7. Inelastic features at the deformation zone beneath the indent, (a) intra-lamellar cracks and splat sliding (see markers); (b) fracture of splats which leads to smaller fragments of material capable of accommodating larger amounts of inelastic deformation; (c) indented surface at the contact boundary between specimen and indenter. examined here; however, if the typical grain size is considered to be $\sim 10 \mu \mathrm{m}$ (see the length of the lamellae in Fig. 3c), the contact area would sample $\sim 5$ grains at the indented surface. As a result, differences in crystallographic orientation between individual grains may not have a major effect on the present measurements. By repeating the indentation tests at different locations of the coating surface, the scatter in the inferred elastic modulus $E$ is obtained. The scatter for all coatings is listed in Table 1 .

\subsection{Some observations of inelastic deformation processes}

As noted earlier, the present indentation technique enables us to distinguish between the elastic and inelastic responses of the material. The mechanisms which might be envisioned for the development of inelastic flow in plasma-sprayed materials are inter- and intrasplat fracture, void coalescence, and metal plasticity (i.e. dislocation motion and twinning which may be particularly active in the case of $\mathrm{Ni}-\mathrm{Cr}-\mathrm{Al}-\mathrm{Y}$ ). By comparing the $C-P$ curves of VPS and APS Ni-Cr$\mathrm{Al}-\mathrm{Y}$, it is evident that the VPS material remains purely elastic while the APS deposit shows signs of inelastic flow as $C$ decreases with $P$. This indicates that, since splats are not detected in VPS $\mathrm{Ni}-\mathrm{Cr}-\mathrm{Al}-\mathrm{Y}$, the marked inelastic flow detected in APS $\mathrm{Ni}-\mathrm{Cr}-\mathrm{Al}-\mathrm{Y}$ has to do mostly with the deformation of its lamellar microstructure.

In order to investigate the mechanisms underlying inelastic deformation in plasma-sprayed materials, APS $\mathrm{Al}_{2} \mathrm{O}_{3}$ deposits were selected to conduct a study of microstructural damage directly underneath the indent [14]. For this study, specimens were cut in half and each of the cross sections was polished. The two pieces were then clamped face-to-face and mounted in a resin mold. Indentation tests were conducted along the trace of the interface between the bonded blocks of material. Finally, the blocks were separated by dissolving the bonding material in trichloroethane, and the cross-sections were examined by SEM [14]. As dislocation plasticity can be ruled out in alumina ceramics, these observations are expected to provide evidence of deformation micromechanisms which are related to the lamellar structure of APS materials.

The results of such experiments, shown in Fig. 7, are for a peak load of $500 \mathrm{~N}$ and a spherical indenter of WC-10 wt.\% Co of $9.5 \mathrm{~mm}$ in diameter. Although similar observations can be made for lower loading levels, the size of the deformation zone below the indent decreases strongly with a decrease in peak load. This makes it desirable to select large spherical indenters and large peak loads to facilitate observation of the deformation zone (it is noted that as in the case of the results in [7], loading to $\sim 500 \mathrm{~N}$ resulted in plastic deforma- 
tion of the metallic substrate). Fig. 7a shows an area located at $\sim 500 \mu \mathrm{m}$ from the center of the contact region in the radial direction (depth $\sim 50 \mu \mathrm{m}$ ). The figure shows opening of intra-lamellar cracks throughout groups of neighboring splats. The opening causes sliding between splats. Fig. $7 \mathrm{~b}$ shows an area of the cross-section which is at depth of $\sim 10-20 \mu \mathrm{m}$ underneath the indented surface. At this location, inelastic deformation becomes more evident as the splats are affected by both inter- and intra-lamellar fracture, reducing the original lamellae to smaller fragments of material. Fig. 7c shows the indented surface at the contact area (this observation is conducted along the direction of the applied load and not at the cross-section of the specimen). The micrograph shows crushing of material which leads to the formation of loose particles. It is noted that the delamination of the coating by the growth of macrocracks (due to the presence of weak areas induced by plasma-spray interruptions [7]), was not detected in the present work. Such weak areas were not present in the coatings under study as their thickness is smaller than that reported in [7], thus, interruptions of the spray sequence imposed to prevent overheating of the substrate were not used here (Section 2).

\section{Concluding remarks}

Accurate measurements of the Young's modulus $(E)$ of plasma-sprayed materials were carried out using instrumented spherical micro-indentation. The presence of residual stresses in plasma-sprayed coatings does not influence the evaluation of $E$ by instrumented spherical indentation because the $P-h$ curves are measured primarily within the elastic contact regime. As $E$ is evaluated in such initial regime, the measurements are not influenced by the inelastic response (microcracking) induced in the materials at larger loads.

The values of $E$ for APS deposits are much lower than those for fully dense materials of similar composition. VPS deposits have larger values of $E$ than APS deposits to the point where $E$ can become, in some cases, similar to that of fully dense materials. The low values of $E$ in APS deposits are due to the large amounts of porosity as well as to the presence of interand intra-lamellar microcracks in the as-sprayed materials (i.e. defects which were already present prior to indentation experiments). The increase in elastic modulus in metallic and intermetallic coatings processed by vacuum plasma-spray is due to the homogenization of the microstructure (by self-annealing at high temperature) which may lead to the removal of the lamellar microstructure and microcracking.

When compared with prior spherical macro-indentation methodologies, instrumented micro-indentation en- ables the mechanical evaluation of thin coatings (of $\sim 100 \mu \mathrm{m}$ thick) from a single experiment, where the influence of the substrate on the elastic and inelastic responses can be circumvented. The assessment of the capacity of the plasma-sprayed material to undergo inelastic flow is another aspect that can be studied by recourse to instrumented spherical micro-indentation. This is achieved by measuring the amount of permanent deformation in the $P-h$ loops or by analysis of the $C-P$ curves on loading.

The results show that plasma-sprayed coatings are strongly susceptible to the development of plasticity. This occurs to the point that the amount of inelastic flow in APS intermetallic and ceramic coatings could be comparable to that induced in a low carbon steel under similar contact conditions. APS materials undergo larger amounts of inelastic deformation as compared with VPS materials. Present results show that the lamellar microstructure of APS materials is a critical factor for such behavior. The onset of inelastic flow in APS metallic coatings occurs at loading levels below those where plasticity commences in VPS or fully dense materials of similar composition. This indicates that inelastic deformation is promoted by mechanisms which are associated with the lamellar microstructure of APS materials. These mechanisms involve microcracking of neighboring splats and inter-splat sliding. At larger levels of compressive loading, microcracking causes a break down of the lamellar structure into smaller fragments of material, which further enables the accommodation of increasing amounts of inelastic deformation.

\section{Acknowledgements}

This project was supported in part by the MRSEC program of National Science Foundation DMR 9632570 funded at the State University of New York at Stony Brook and MIT. J. Alcala wishes to thank 'Generalitat de Catalunya' and DGR for financial support. F. Gaudette's work was partially supported by the Office of Naval Research Grant N-00014-94-1-0139 to MIT. The authors thank Dr A.E. Giannakopoulos for helpful discussions.

\section{References}

[1] H. Herman, Sci. Am. 256 (1988) 112.

[2] A. Ohmori, C.J. Li, Thin Solid Films 201 (1991) 241.

[3] T.E. Strangman, Thin Solid Films 127 (1985) 93.

[4] R.A. Miller, Surf. Coat. Tech. 30 (1987) 1.

[5] S. Sampath, H. Herman, J. Thermal Spray Tech. 5 (1996) 445.

[6] S. Leigh, C. Lin, C.C. Berndt, J. Am. Ceram. Soc. 80 (1997) 2093.

[7] A. Pajares, L. Wei, B.R. Lawn, N. Padture, C.C. Berndt, Mater. Sci. Eng. A208 (1996) 158. 
[8] J. Alcalá, A.E. Giannakopoulos, S. Suresh, J. Mater. Res. 13 (1998) 1390.

[9] S. Suresh, A.E. Giannakopoulos, Acta Mater. 46 (1998) 5755.

[10] S. Suresh, J. Alcalá, A.E. Giannakopoulos, US Patent Application, Filed April 1996.

[11] D.B. Marshall, T. Noma, A.G. Evans, J. Am. Ceram. Soc. 65
(1982) C-175.

[12] S. Kuroda, T.W. Clyne, Thin Solid Films 200 (1991) 49.

[13] O. Kesler, M. Finot, S. Suresh, S. Sampath, Acta Mater. 45 (1997) 3123.

[14] F. Guiberteau, N.P. Padture, B.R. Lawn, J. Am. Ceram. Soc. 77 (1994) 1825. 